\title{
Judicialização da vida e penas e medidas alternativas: composições, tensionamentos, problematizações
}

\section{Legalization of life and sentences and alternative measures: compositions, tensioning, problematizations}

\author{
Fabiana Davel Canal* \\ Centro de Referência da Assistência Social - CREAS, Castelo, Espírito Santo, Brasil \\ Gilead Marchezi Tavares** \\ Universidade Federal do Espírito Santo-UFES, Vitória, Espírito Santo, Brasil
}

\begin{abstract}
RESUMO
O objetivo deste artigo foi considerar a "Judicialização da Vida", analisando as práticas que dão suporte a este fenômeno, assim como seus efeitos sobre os modos de vida de pessoas que estão em contato direto com a justiça, cumprindo penas ou medidas alternativas (PMAs). Para tanto, usou-se como metodologia o diário de campo contendo a vivência dos autores no curso de formação em Direitos Humanos para pessoas que cumprem PMAs, além de cinco entrevistas semiestruturadas com os integrantes do referido curso. Com base na Arqueogenealogia de Foucault, buscou-se encontrar as práticas que são construídas, as verdades afirmadas, as instituições acionadas, etc. Observa-se, assim, a judicialização como um fenômeno complexo, que compreende o fácil acesso ao judiciário, o que possibilita solicitar sua intervenção em nossas vidas, além de valorizar a cultura punitiva, fazendo de nós juízes cotidianos.
\end{abstract}

Palavras-chave: judicialização, penas alternativas, arqueogenealogia.

\section{ABSTRACT}

The aim of this article was to consider the "Legalization of Life" by examining the practices that support this phenomenon, as well as its effects on the lifestyle of people who are in direct contact with the justice system, serving Alternative Measures Programs (AMPs). In order to do so, the methodology used was the research diary, containing the authors' experience on the Human Rights course for people serving AMPs, as well as five semi-structured interviews with members of that course. Based on the Archeogenealogy by Foucault, there was an effort to identify the built practices, the truth stated, the institutions used and so on. Therefore, the judicialization is seen as a complex phenomenon that includes easy access to the judiciary, what allows requesting its intervention in our lives, as well as appreciating the punitive culture, making us every day judges.

Keywords: legalization, alternative measures, archeogenealogy. 


\section{0 cumprimento de penas e medidas alternativas: situando um campo de intervenção}

No caminho que percorreremos neste trabalho, que é o resultado parcial de uma pesquisa de mestrado em Psicologia Institucional, trataremos do cumprimento de penas e medidas alternativas (PMAs), das práticas que as compõem e de seus efeitos nos modos de vida dos "beneficiários" ou "apenados" (pessoas que cumprem PMAs), propondo como campo de análise os processos contemporâneos de "Judicialização da Vida". O campo de análise, desse modo, refere-se aos processos que envolvem determinado campo de intervenção (no nosso caso o cumprimento de PMAs) e efetuam formas mais ou menos estáveis de enunciação e de visibilidade, ou seja, o campo de análise diz respeito à tentativa de compreensão e de inteligibilidade dos determinantes do campo de intervenção.

Compreendemos o campo de pesquisa como campo de intervenção, partindo da metodologia da Pesquisa-Intervenção (Rocha \& Aguiar, 2003). Dessa maneira, falaremos sempre de uma produção de dados e nunca de uma "coleta" de dados. Acreditamos que o pesquisador, ao estar no campo, o produz. Assim, neste trabalho não acreditamos na separação entre objeto e pesquisador, teoria e prática; não acreditamos na neutralidade do pesquisar; nem numa realidade já dada a ser descoberta pelo detentor do saber, o cientista. Afirmamos que o pesquisar constrói a realidade, produzindo movimentos; nela, pesquisador e campo transformam-se no decorrer do percurso e a teoria funciona como ferramenta, sendo engendrada no meio social. Trata-se, ainda, da afirmação de uma política científica comprometida com a realidade social e com os processos locais e as situações casuais das relações microcósmicas que reverberam no campo ampliado das forças políticas.

Traremos para a análise as falas advindas de nossa vivência em um curso de Educação em Direitos Humanos, que tem duração total de 87 horas, intitulado "Exercendo Cidadania". O Curso funciona como Prestação de Serviços à Comunidade (PSC) para pessoas que cumprem Penas e Medidas Alternativas na cidade de Vitória - ES. Decidimos por participar do curso, oferecido pela Prefeitura Municipal de Vitória, em parceria com a Vara de Execuções de Penas e Medidas Alternativas (VEPEMA), com a finalidade de conhecermos essa forma de cumprimento de PMAs.

Nossa atenção voltou-se para a 11 1 a turma do curso, que aconteceu de outubro a novembro de 2010. Nesse período, todas as noites, de segunda à quinta, das 19 às 22 horas, frequentamos o curso de formação junto com os apenados que são encaminhados pela Vara de Execução das Penas e Medidas Alternativas (VEPEMA) para a referida PSC. Na sala, 15 pessoas em média, com idades entre 24 e 58 anos, em sua grande maioria homens (no máximo três mulheres) 
frequentavam o grupo.

Usamos o diário de campo como nosso instrumento privilegiado de produção de dados nesse momento da pesquisa. Nele, foram registrados sistematicamente os movimentos cotidianos: o que aconteceu, as falas, as perguntas, as inquietações, as sensações. Registramos, ainda, nesse instrumento, as falas proferidas em um evento realizado pela VEPEMA direcionado para os estabelecimentos que recebem os prestadores de serviço (os apenados).

A partir da vivência no projeto "Exercendo Cidadania", percebemos a importância, ainda, de andar por outros caminhos. Deste modo, estendemos nossa caminhada ouvindo um pouco mais as histórias daqueles que passaram pelo curso, em sua $11^{\text {a }}$ turma. Como a turma era grande, escolhemos alguns integrantes daquele grupo para realizarmos entrevistas semiestruturadas. Apostamos que elas poderiam nos levar para caminhos que ainda não tínhamos tido contato durante o curso e, quem sabe, ajudar-nos a entender um pouco das paisagens que encontramos ao longo daqueles dois meses de caminhada juntos.

Mas quais pessoas seriam entrevistadas por nós? Nossa escolha deuse da seguinte forma: a assistente social e o psicólogo do projeto deram-nos o nome e o telefone de todos que participaram da 11 a turma. Ligamos e marcamos com oito participantes, que mostravam disponibilidade de encontrar-se com a pesquisadora. Em dois de nossos encontros, os participantes não compareceram, nós remarcamos e eles, mais uma vez, não foram ao nosso encontro para a realização da entrevista. Em um caso, entramos em contato pelo telefone, esperamos o retorno via email para marcarmos a entrevista (forma escolhida pelo apenado para o contato), mas esse não aconteceu. Realizamos, dessa forma, cinco entrevistas semiestruturadas, que foram gravadas mediante autorização por meio de um termo de consentimento livre e esclarecido e transcritas integralmente.

As cinco entrevistas realizadas tinham perguntas referentes à condenação, às pessoas do judiciário que encontraram depois disso, ao cumprimento das PMAs no espaço do curso e em outros lugares (caso tivessem cumprido as horas também em outros estabelecimentos), ao possível preconceito social pelo fato de estarem "condenados", entre outras. Nós levamos um roteiro, mas deixamos espaço para que outras questões pudessem ser levantadas por eles ao longo de nossa conversa.

Andamos, então, ao lado de uma mulher, quatro homens e muitas histórias. Ela e eles dispuseram-se a deixar algumas horas de suas ocupações (quatro deles nos encontraram durante o expediente de trabalho, em seus locais de laboro e um foi até a universidade depois de um dia corrido de afazeres) para partilhar conosco um pouco de suas vidas. Personagens com profissões e classes sociais diferentes, 
que preferimos não revelar, pois poderiam ter colados suas histórias a uma identidade (de classe, de gênero, de etnia, de escolaridade etc.), não sendo essa nossa intenção. Optamos por falar aqui de histórias que são deles, certamente, mas que poderiam ser de muitas outras pessoas.

Como analisar nossas conversas? Michel Foucault é quem nos dá ferramentas para construirmos nossas análises que se basearão nos caminhos percorridos e nas falas proferidas nesse caminhar. Para ele, os discursos são sempre raros, ou seja, dizemos e fazemos em uma época, muito pouco frente a tudo que pode ser dito e feito. $O$ autor de uma fala é apenas "uma posição a ser ocupada" (Foucault, 2000, p. 33) e o sujeito que pronuncia um discurso "(...) recortará, em tudo o que poderia ter dito, em tudo o que diz todos os dias, a todo momento, o perfil ainda trêmulo de sua obra" (Foucault, 1996, p. 2829) dando a inserção do mesmo no real, ou seja, forjando sua materialidade.

Foucault diz que o discurso não é produto da retórica, não é produzido por algo ou alguém; que ele não é formulado por uma interioridade. Para o autor, o discurso é um conjunto de enunciados que pertencem a uma determinada época e só são manifestos porque naquele momento há condições para que ele exista.

Não passar do discurso para seu núcleo interior e escondido, para o âmago de um pensamento ou de uma significação que se manifestariam nele; mas a partir do próprio discurso, de sua aparição e sua regularidade, passar as suas condições externas de possibilidade, àquilo que dá lugar a série aleatória de acontecimentos e fixa suas fronteiras (Foucault, 1996, p. 53).

Foucault diz ainda que os enunciados ou as práticas discursivas relacionam-se com as práticas não-discursivas. Para Deleuze (1998), em seu livro em homenagem a Foucault, as práticas discursivas estão no terreno das "enunciabilidades", enquanto às nãodiscursivas, no das "visibilidades"; ambos são produtos das relações de poder. Quando Foucault (1985) fala de poder, e falamos com ele neste trabalho, não traz como Aparelho de Estado ou como algo que alguns detém e outros não, mas como "multiplicidade de correlações de força (...) o jogo que, através de lutas e afrontamentos incessantes se transforma, reforça, inverte" (p. 88-89), como uma ação sobre outra ação, ou ainda, "o nome dado a uma situação estratégica complexa numa sociedade determinada" (p. 89), que pode se instrumentalizar nos estabelecimentos estatais, nas leis, entre outros. Uma fala, para Foucault, nunca é despretensiosa, nunca vem sozinha, mas, a partir dela, várias verdades são ativadas, várias formas de vida historicamente produzidas entram em cena (Almeida, 2005). Os discursos carregam consigo práticas sociais, econômicas, culturais, 
políticas, sendo assim, eles próprios, ações, práticas, intimamente ligados às instituições ${ }^{2}$ (Alves, 2008).

A curva-enunciado integra na linguagem a intensidade dos afetos, as relações diferenciais de força, as singularidades de poder (potencialidades). Mas é preciso então que as visibilidades integrem também, de modo completamente diferente, na luz. (...) Pois as visibilidades, por sua vez, à luz das formações históricas, constituem quadros, que são para o visível o que o enunciado é para o dizível ou legível.... O diagrama das forças se atualiza ao mesmo tempo em quadrosdescrições e curvas-enunciados (Deleuze, 1998, pp. 87-88).

Para Foucault (1996), há uma restrição na ordem do discurso, podendo proferi-los apenas pessoas que são qualificadas e em contextos específicos, sendo seguidos por definições de regras, rituais, símbolos, signos que fixam sua eficácia e seus efeitos a quem se dirigem.

Pensamos, em uma proposta metodológica que compreende a arqueologia e a genealogia, sendo, assim, arqueogenealógica. $\mathrm{Na}$ arqueologia, Foucault faz uma análise do discurso em sua constituição histórica, e, partindo dos enunciados, procura ver quais verdades são acionadas nos discursos. Opera, nesse sentido, na ordem do saber (Almeida, 2005). Já a genealogia, analisa os discursos em sua capacidade de constituição, de positividade, de produção estratégica (Foucault, 1996), atuando na esfera do poder.

Sendo a arqueo-genealogia uma análise das práticas e formações discursivas centrada na descrição de enunciados, nosso trabalho consiste em colocar as coisas "efetivamente ditas" em "situações relacionais": os discursos, sendo eles próprios já uma prática, ostentam práticas (institucionais) que Ihe são coextensivas - é do interior das instituições que os discursos saem e a elas retornam e é também no interior das instituições que os sujeitos, por assim dizer, se instituem e subjetivam (Alves, 2008, p. 4).

Dessa forma, ao analisarmos os discursos de nossos entrevistados e, ainda, as PMAs através dos relatórios, portarias, leis e documentos produzidos (que também são discursos de uma época), buscamos encontrar nas coisas ditas (e escritas) quais práticas são construídas, que verdades são afirmadas, quais instituições acionam, quais os lugares ocupados por esses sujeitos, o que é permitido a eles dizer e o que eles precisam calar e que efeitos são produzidos por esses discursos.

Queremos chamar a atenção para os efeitos das práticas sociais que 
se materializam nos dispositivos jurídicos (foco deste trabalho), mas que são resultado de processos de subjetivação contemporâneos, ou seja, de formas de pensar e viver produzidas historicamente e que se tornam "expressões-em-nós" do tempo em que vivemos (Machado, 1999).

\section{A J udicialização da vida: compondo um campo de análise}

\subsection{A questão do acesso ao judiciário}

Cada vez mais assistimos as pessoas recorrendo ao J udiciário para a resolução dos diferentes conflitos que encontram em seu dia a dia como exemplo, podemos citar o número crescente de processos nas mais diversas áreas.

Vianna (1999) aponta que não só as pessoas recorrem cada vez mais ao Judiciário a fim de que se cumpram as leis, como também há uma expansão da capacidade normativa do sistema jurídico com a criação de leis que traduzam os interesses - individuais ou de grupos em direitos. Estes armam o Judiciário, cada vez mais, de meios e modos para o exercício de uma intervenção na vida da população, inclusive em seu âmbito privado.

Vimos esse movimento de forma intensa nas décadas de 70 e 80 , momento no qual movimentos sociais, além de lutarem pela redemocratização do Estado Brasileiro (pois estávamos vivendo o período do Regime Militar), também lutavam por emprego, terra, habitação, saúde, entre outros. Eles buscavam, ainda, mudanças legislativas que garantissem direitos, sobretudo para as minorias e para as populações marginalizadas (Silva, 2002).

Reflexo jurídico dos movimentos sociais foi a promulgação da Constituição de 1988, que estabelece a criação da defensoria pública, "inaugurada" com o encargo de defender em juízo aqueles que não dispunham de recursos financeiros para arcar com os custos do processo sem sacrificar o seu sustento e o de sua família, o que possibilitava uma maior aproximação desse público com o Sistema Judiciário.

\subsection{Os Braços da J udicialização}

\subsubsection{A cultura punitiva e a criminalização: a juridicialização da vida}

Coimbra (2009) alerta-nos que a demanda crescente pela criação de leis não é exclusiva do passado, mas que se atualiza cada vez mais em nossos dias, nas vozes de diversos atores sociais: 
Os movimentos sociais acreditam e apregoam como missionários que a impunidade é a principal causa da violência ontem e hoje e pedem mais leis, aplaudindo a rigidez e a dureza da Lei Maria da Penha, por exemplo, e solicitando que uma lei federal defina "o funk como movimento cultural e musical de caráter popular" (Coimbra, 2009).

Os dispositivos legais inscrevem-se em regimes de verdade, podendo ser utilizados das mais variadas formas e em nome de diversas práticas (Marafon, 2010). São fundamentais na implementação da tecnologia biopolítica ${ }^{1}$, possibilitando uma interferência direta na vida da população, pois, a partir dos códigos, o Estado tem como rastrear, por exemplo, quais indivíduos, pertencentes a quais grupos sociais, não cumprem uma determinada norma. Tem-se um mapa contendo os elementos críticos, desviantes ou em vias de desviar, que permitem "punir ou regular todos os fatores de conjunto que possam ocasionar uma subtração das forças da população e, consequentemente, do Estado" (Caliman, 2001, s/p). É através, por exemplo, das estatísticas de determinada região, que se opta por implantar determinadas políticas em umas comunidades e outras em locais diferentes.

Nilo Batista (2007) afirma que a sensibilização social decorrente da promulgação de uma lei, sem dúvida, provoca um debate sobre as opressões vividas por diferentes públicos (em seu artigo, ele fala das mulheres que sofrem violência doméstica, mas tomamos emprestada sua análise e a estendemos para as minorias como os homossexuais, os negros, as crianças etc.), mas que pode ser neutralizado pelo "simplismo de sua tradução legal" (pp. 15-16) e sua efetivação por meio de uma intervenção punitiva - podendo ser a restrição de direitos (Penas e Medidas Alternativas) ou, dependendo do caso, a restrição de liberdade (prisão). E, "produzindo a necessidade das leis, a moral em nosso mundo expande-se sobre o disfarce da ética. Fala-se de ética, mas aplica-se a moral: julga-se, prescreve-se, tutela-se, pune-se" (Coimbra, 2009, p. 4).

Entendemos que a luta pela efetivação dos direitos é imprescindível, mas pode estar atuando tendo por base quase que exclusivamente a vingança. Não se opera uma inversão, uma problematização dos modos de vida contemporâneos, mas se age por ressentimento. Convoca-se para o auxílio das minorias "o mesmo veneno" (Batista, 2007, p. 14) que se quer combater.

Disso decorre que nossas lutas pela reinvindicação de direitos formais e cidadania para todos são compreendidas no plano da consciência e dependem, talvez, da "tomada de consciência", expressão tão propalada por várias forças dos diversos movimentos sociais. Sem minimizar os esforços dessas lutas, é 
preciso atentarmos para o perigo de, mesmo assim, permanecermos na anestesia e impotência pelas ações da dimensão moral (Marafon, 2010, p. 8).

Autores como Batista (2009), Coimbra (2009), Passetti (1999, 2006, 2009), entre outros, lembram-nos que as formas que tomam nossas relações sociais na atualidade são engendradas em uma cultura punitiva, talvez só comparada com a época da inquisição e do nazismo, que prega o castigo e a vingança como forma de justiça social. Desejo de punir que traz consigo o ranço de práticas históricas - como exemplo, podemos citar a violenta colonização de nosso país, a escravidão vivida de várias formas e a ditadura militar (Batista, 2009).

Vera Batista (2009), ao analisar a cultura punitiva, aponta a figura da vítima como sendo um de seus componentes estratégicos. Através da vitimização, produz-se, como numa simbiose, a criminalização de comportamentos e de formas de vida. Criminalização que entendemos ser um "dos braços" da judicialização. Na história da justiça penal, Passetti (1999) lembra-nos que, quase nunca se pensa na justiça para a "vítima". O que se quer, na maioria das vezes, é que se efetive um sistema de vingança.

Nesse ponto, lembremos das análises que Foucault fez, trazendo a história. Do século XVI ao XVIII, o poder de punir era exercido pela vontade do soberano, que possuía o "direito de apreensão das coisas, do tempo, dos corpos" (Foucault, 1985, p.128) e, inclusive, da vida, que era uma de suas propriedades. A insígnia real era: "causar a morte ou deixar viver" (Foucault, 1985, p. 128) àqueles que 0 ameaçavam. O poder de morte do príncipe era demonstrado quando ele enviava seus súditos para guerrearem em defesa de seu reino (Junges, 2010) ou quando se vingava através dos suplícios. Essa era a forma de vingança da sociedade soberana.

Com o tempo, "O poder punitivo vai precisar de novas ideias e novas técnicas para dar conta da concentração de pobres que o processo de acumulação do capital provocou" (Batista, 2009, p. 25). Assim, na sociedade disciplinar, os reformadores penais pedem o fim das vinganças arbitrárias do príncipe e um remanejamento do poder de punir de forma que ele torne-se mais eficaz, regular e constante (Foucault, 1979).

O castigo passou a ser usado como punição e tendo como objetivo a correção de condutas desviantes. Na sociedade disciplinar, por exemplo, instaura-se a norma e atribui-se a determinados comportamentos o status de "normais" e, consequentemente, a outros, que fogem à norma, o de "anormais". Aqueles que não se inscrevem na norma são punidos, a fim de que se reestabeleçam, atingindo o padrão estabelecido pela norma.

Assim, o castigo serviria para a docilização dos corpos e das almas. 
Há tempos, ele efetiva-se privilegiadamente em estabelecimentos com regime fechado como prisões, manicômios, hospitais. Hoje, com a tônica "ditada" pela sociedade de controle (Deleuze, 1992), o castigo concretiza- se em espaços a céu aberto. Como exemplo temos as Penas e Medidas Alternativas, que "educam" os corpos transgressores no nível de uma advertência verbal, por meio da subtração dos bens materiais ou, ainda, através do trabalho forçado, pela caridade imposta (nada melhor que a caridade para "limpar a alma!"), em estabelecimentos determinados pela justiça.

Ruins pelo fato de eu estar passando por uma coisa que eu não me sinto a vontade de estar fazendo aquilo ali porque... Eu sempre quis fazer trabalho voluntário, mas não dessa forma, não obrigatoriamente, de estar ali, fazer e pronto acabou. De ter que cumprir as horas (Entrevista 3).

Não, tudo bem, o que tiver que fazer eu faço até cumprir isso [a Pena Alternativa]. Inclusive, depois que as aulas voltarem [na Casa dos Autistas, local em que ele prestava serviço], que não for obrigação, eu vou vir aqui como voluntário (Entrevista 4).

Didaticamente, nada é comparado à PSC. Quando os apenados chegam à VEPEMA o que eles querem, na maioria das vezes, é pagar o delito com cesta básica (em especial os que têm uma condição financeira melhor). Mas a gente nega, porque é importante ele pensar sobre o que fez (Diário de campo - Fala em uma mesa no VIII Fórum de Discussão de Penas e Medidas Alternativas - 05 de novembro de 2010).

E essas sanções penais operacionalizadas nos estabelecimentos que recebem as pessoas que cumprem serviços para a comunidade são formas de castigar, longe da cadeia, aquelas pessoas, produzindo outro modo de castigo, de encarceramento, que parte de outra lógica.

Mas uma pessoa, como eu disse pra um juiz lá nessa reunião, quando bota uma pessoa que esteja ali, ela é uma apenada, e vai empurrar maca dentro do hospital, eu não acho que aquilo dali, não é proveitoso pra ninguém aquilo dali. Então um juiz lá disse "parece mais um castigo". E eu disse que justamente é um castigo. Você empurrar maca, você vai aprender o que? (Entrevista 2).

Melhor do que estar preso, muito melhor. Mas só que eu me sinto assim, deprimido, não me vejo fazendo aquilo ali por vontade própria (Entrevista 3). 
O Direito, as leis, seriam a formalização dessas normas sociais que, historicamente produzidas, são alteradas por cada época e sociedade. Dessa forma, estabelecemos, a cada dia, quais comportamentos são considerados desviantes da norma e instrumentalizamos os códigos jurídicos com novas formas de lidar com eles. Numa perspectiva judicializante, nós definimos padrões de condutas para crianças, jovens, famílias, trabalhadores... (Marafon, 2010).

No trajeto percorrido entre sociedade disciplinar e sociedade de controle percebemos que não se alterou o sentido do castigo e da recompensa como formas privilegiadas de sociabilidade (Passetti, 1999). Passetti (2009), em outro texto, lembra-nos de que quem educa ocupa um lugar de autoridade, ou seja, possui um papel investido de poder, oferecendo recompensas pela docilidade, além de ameaçar e aplicar castigos àqueles que não se dobram ao que the foi imposto. Julgamentos e castigos para com os outros, mas também para conosco. Somos nós os nossos piores juízes. É preferível, muitas vezes, o julgamento dos outros do que quando somos nós os juízes de nós mesmos.

Na realidade é o seguinte: eu me senti, eu me puni todo esse tempo, eu vinha me punindo todo esse tempo. Então eu acordava, às vezes, à noite, e ficava me recordando - isso nesse período que eu te falei, de 2002 à 2009, eu acordava; no dia a dia, quando eu via alguma coisa semelhante, eu voltava naquele pensamento, naquelas coisas. Então, eu me punia muito! E a sentença ela veio de alguma forma pra me tirar um pouco, me aliviar. Porque aí veio uma sentença diferente, não minha, né, externa. Então, foi meio complicado, mas eu não senti assim, de fato, condenado. Eu sabia que eu tinha que pagar, eu devia pro Estado, eu passei a ter esse dever pro Estado ... (Entrevista 2).

Mas foi tranquilo porque eu hoje acho até que ela foi até um pouco branda. Porque eu condenaria, tenho condenado, isso tem ocorrido com outras pessoas, tenho visto isso na mídia, eu tenho condenado... Então, não tem o porquê eu não condenar o que eu fiz. Não o fato em si, mas as consequências que poderiam ter tido com a minha ação (Entrevista 2).

Porque eu não culpo eles [juiz e técnicos do judiciário] de nada, né, a culpa maior foi minha, de me envolver com um pessoa que eu não conhecia. O princípio de tudo o que aconteceu foi tudo falha minha (Entrevista 3).

A essas práticas que confiam as atividades de julgar, o julgamento das condutas, Augusto (informação verbal, 2011) dá o nome de 
Juridicialização da vida. Na mesma fala proferida pelo autor, ele discute que essas formas de julgamento, que antes eram mantidas no interior dos estabelecimentos disciplinares, agora são distribuídas "aos quatro ventos", solicitando que a população participe desse julgamento coletivo (questão que nos deteremos de forma mais detalhada adiante), produtor de corpos dóceis e mentes assujeitadas.

O vivo produtivo das disciplinas passa a dar lugar ao vivo participativo. Assim, perpetua o ordinário do tribunal nas práticas corriqueiras de nossas vidas, fazendo-nos ora juízes, ora acusadores, ora algozes ou vítimas, e se espalham e reproduzem as práticas de tribunal. Mais do que introjetar o julgamento, fomenta-o. Há uma democratização do tribunal no interior da comunidade local, no interior da escola etc (Augusto, informação verbal, 2011).

Consideramos importante frisar que o termo Judicialização é comumente utilizado para definir a expansão do judiciário nas práticas cotidianas da vida. Nesse sentido, há autores que têm preferido a utilização do termo Juridicialização ou Jurisdicionalização. Segundo Bruno (2009), "o conceito de Jurisdicionalização [pautado nas concepções de Rojo] é o único capaz de dar conta do duplo movimento, abarcando tanto à judicialização como a desjudicialização como dimensões inseparáveis da mesma demanda: a reivindicação de uma instância simbólica chamada a dizer o que é justo" (p. 51). Este duplo movimento, trazido por Bruno (2009), é entendido como sendo de um lado um grande movimento de submissão populacional as demandas do Poder Judiciário, e do outro lado o movimento de dissolução de conflitos sem a interferência de juízes, porém pautada em valores jurídicos.

Uma maior participação da comunidade no Sistema de Justiça foi um tema que, vez ou outra, eratrazido para o debate nos grupos que acompanhamos. Essa participação crescente diz respeito à fiscalização e controle, pela comunidade, de diversas situações que, normalmente, são função dos aparatos jurídicos. Um dos apenados discorda que esse seria um papel que deveria ser atribuído para a população, fazendo uma análise das consequências que esse fato poderia acarretar para a vida em sociedade.

Dizia ele:

Será que não é inverter para a população um dever que o Estado tem? Isso é aliviar a questão para o Estado. E a contribuição [financeira] que a população dá para o Estado garantir sua segurança? Acho que nós temos que cobrar do Estado, porque, se não, ele acaba não fazendo nada. É perigoso usar a população, porque a gente pode dar margem 
para a seguinte situação: um cara rouba um carro. Pessoas veem, correm atrás dele e, como faz a polícia, vai lá e bate nele. É o povo fazendo a justiça! (Fala de um dos integrantes do grupo, Diário de campo, 03/11/10).

Uma maior participação da comunidade no Sistema de Justiça Criminal é um dos objetivos das PMAs (Brasil, 2006). Elas buscam, "não punir menos, mas punir melhor" (Foucault, 1979, p. 79). Essa mesma frase é utilizada por Foucault para falar da punição efetivada por uma nova economia de poder, na transição da soberania para a prisão, e foi recentemente utilizada em uma campanha do Conselho Nacional de Justiça (CNJ, 2010) para a promoção das Penas e Medidas Alternativas, no sentido de convencer a população de que não estaríamos deixando de punir com a adoção dessas medidas penais. Entretanto, ao contrário do autor que aponta para o refinamento dos mecanismos de poder e de intervenção na vida da população, o CNJ aponta que, com as PMAs, teríamos uma forma melhor no sentido de uma prática punitiva mais evoluída, mais efetiva.

Além disso, a grande dificuldade em relação à aplicação das PMAs é a sensação de impunidade gerada no meio social que, imersa em uma cultura de duros castigos, vê os presídios ou até mesmo a pena de morte, como as formas ideais de punição.

Lidar com o volume de processos que a VEPEMA tem hoje é difícil. Sem a parceria de vocês [da comunidade presente no evento] as Penas Alternativas não existiriam e as prisões estariam 10 vezes mais cheias do que estão hoje.... Em 2001 tínhamos 990 pessoas cumprindo as PMAs na Grande Vitória. Em 2010 esse número chega a 14.600... Nosso objetivo hoje é fazer vocês pensarem sobre o papel de vocês nessa história (Diário de campo - Fala no VIII Fórum de Discussão de Penas e Medidas Alternativas para os representantes dos estabelecimentos que recebem os apenados, 05/11/2010).

Outra dificuldade apontada é a ineficiência, vista por parte dos juristas, devido à dificuldade de fiscalização pelos órgãos competentes (Brasil, 2009). Para sanar esta questão, os especialistas defendem a criação de núcleos ou centrais destinadas ao monitoramento e fiscalização dos apenados que cumprem esse tipo de sanção jurídica. Segundo dados do Ministério da Justiça, no ano de 2009, o Brasil já contava com 389 núcleos de monitoramento de PMAs e Vitória, desde 2001, conta com uma Central de Penas e Medidas Alternativas que, entre outras coisas, é responsável pela fiscalização dos apenados.

E, se cada dia mais somos convocados a participar do judiciário, introjetamos as penalidades dos juízes do Direito, e nos tornamos 
juízes cotidianos: em nossas casas, usamos o castigo como forma de ensino para nossos filhos, utilizando-o nos momentos em que não praticam as atitudes esperadas. Castigos que podem ser físicos, mas que nem sempre são; nas escolas, os mestres impõem aos seus alunos penalizações como notas baixas, por exemplo, que o farão repetir de ano, por não terem conseguido reproduzir o conteúdo ensinado na prova, como se esperava que eles fizessem; algumas escolas, ainda, tem a "salinha do pensamento", local reservado para que o aluno fique "refletindo" que fez algo julgado como errado.

Educar é cultivar o espírito: formá-lo e fazê-lo adquirir cultura. É transmitir conhecimento, erudição, adestramento e domesticação a cada pessoa para torná-la obediente a comandos que zelam pelo culto e cultivo de uma moral superior. Toda a educação para a obediência requer ameaça e uso de castigos que funcionam como prevenções gerais à manutenção do equilíbrio da sociedade.... A ameaça e o uso de castigos, enfim, geram o medo necessário pra o governo dos pais, dos governantes e dos procedimentos disciplinares (Passetti, 2009, p. 162).

São essas as formas de socialização que, desde cedo, apresentamos às nossas crianças. Elas são expostas muito novas a essa cultura do castigo, que passa a ser visto, depois de um tempo, como algo natural, uma prática normal.

Batista (2012) ainda aponta que a demanda coletiva por castigo e punição, uma "adesão subjetiva à barbárie", proveniente da cultura punitiva, tem como principal metodologia a produção do medo. Sentimento que, como nos lembram Moreira, Figueiredo, Uziel e Bicalho (2010) também é uma construção social. Cada época dita as figuras/situações em que/a quem a sociedade deve sentir medo.

E nada mais eficaz para a propagação desse medo do que sua divulgação pelas mídias: "uma manchete provoca mais iniciativas de agências do sistema penal, provoca mais exercício do poder punitivo do que uma investigação cabalmente concluída, porém longe dos refletores das câmeras" (Batista, 2007, p. 8). É a mídia que fabrica privilegiadamente, por meio de imagens e narrativas, as figuras da vítima e do agressor, "delimitando nosso sentimento de justiça e solidariedade" (Vaz, Sá-Carvalho, Pombo, 2005, p. 22), a quem devemos temer ou ter pena. Moreira et al (2010) demonstram que, as figuras que são produzidas como causadoras do nosso medo são coincidentes as que são propensas a sofrerem criminalização, ou seja, as pessoas que não possuem poder de compra significativo: a saber, os pobres!

O medo que nos referimos produz engajamento subjetivo na desconfiança, de forma que todos passam a desconfiar de tudo e de 
todos; todos temem tudo e todos, querendo sempre se proteger de algo ou alguém. Coimbra (2009) ainda aponta como efeito deste medo a produção de uma forma subjetividade "moralista-policialescapunitiva-paranoica" que, além de moralizar por meio do "julgamento, das prescrições, do clamor por mais leis", produz o "policial em nós" ( $p$. $6)$.

Tornar cada cidadão um vigilante do direito tem produzido relações de ameaça sustentadas no julgamento sistemático entre as pessoas. Todos nos tornamos juízes; todos julgamos e punimos ou pedimos a pena; acreditamos na pena.

Essa vontade de julgar, de sentenciar, apenas expressa o medo em enfrentar o desconhecido, o surpreendente, o vivido. É comum ouvir das pessoas: "E agora? O que fazer? Deixa como está? Não vai acontecer nada?". Nessa pressa em deliberar uma sentença, perde-se o que um acontecimento, mesmo que trágico ou doloroso, pode trazer de diferente, de transformador, muitas vezes a despeito de racionalizações ou temporalidades (Augusto, 2009, p.12).

Assim, ao olharmos para o mundo, muitas vezes, lançamos olhares revestidos pela moral, acionando julgamentos e "bloqueando a processualidade, a problematização e a avaliação, as quais permitiriam acessar o processo de produção" (Marafon, 2010, p. 10) das práticas que constroem realidade.

\subsubsection{A sociedade clama por justiça!}

Tudo e todos na atualidade passaram a ser passíveis de uma resposta jurídica, de uma explicação qualquer a partir dos códigos do direito, que possa porventura justificar a si e as suas ações (Reis, 2010, p. 4).

A judicialização se dá em defesa de costumes e na busca por verdades, que é um dos componentes fundamentais da moral. Essas verdades, como apontamos, podem materializar-se nos códigos jurídicos, por meio das leis e dos aparatos que as sustentam (Tribunais, Prisões, Penas Alternativas, Justiça Terapêutica, entre outros), produzindo modos de vida moralizantes, revestidos pela doutrina do juízo (Reis, 2010).

E o principal poder emergente desse conjunto de "movimentos punitivos vai ser a legitimação da intervenção moral" (Batista, 2009, p. 154), por meio da invasão do Estado penal nas relações privadas, como nas de família ou de vizinhança, havendo o confisco dos pequenos conflitos por parte do Poder Judiciário - outro braço que entendemos ser o da judicialização. Veremos, então, "despontar a figura do juiz em quase todos os aspectos da vida social" (Marafon, 
2010 , p. 2). Cada vez mais um grande contingente de pessoas tem procurado privilegiadamente o sistema de justiça, que é visto como "sistema incontestável de verdade" (Bocco, 2009, p. 117), para a resolução dos mais variados conflitos!

Para exemplificar, vamos trazer a interferência judicial na área da Saúde Mental, retratada por Zimmer (2011), através da internação compulsória de pessoas ditas loucas em espaços asilares (como os ainda existentes hospitais psiquiátricos), baseados na suposta "periculosidade" dessa população e amparados pela Lei 10.216 de 2001, que versa sobre a Reforma Psiquiátrica.

Fato é que se torna crescente e comum, quase banal, que Juízes de Direito decretem, corriqueiramente, sentenças de reclusão de pessoas consideradas loucas, com a finalidade de "tratamento" no Hospital Psiquiátrico, na justificativa de "falta de local apto a recebê-lo" (Zimmer, 2011, p. 37).

Ao procederem de tal maneira, torna-se clara a dificuldade de diálogo entre os juízes e os demais setores da sociedade, como aqueles que lutam por outras formas de se cuidar da doença mental, os familiares e trabalhadores dos serviços substitutivos ao modelo hospitalocêntrico: Ambulatórios, Centros de Atenção Psicossocial (CAPS), Residências Terapêuticas etc. (Zimmer, 2011).

Podemos pensar ainda na busca das pessoas por formas legais de internação compulsória dedependentes químicos.

Atualmente, há uma grande campanha pela abertura de comunidades terapêuticas para usuários de drogas, fato baseado no entendimento de diversos setores da sociedade que o único tratamento eficaz, nesses casos, seria o isolamento das pessoas que passam por situações graves com as drogas. Como o Sistema único de Saúde não possui clínicas de internação suficientes para a grande demanda, muitas famílias recorrem aos juízes para que eles obriguem que o Estado receba essas pessoas nas que existem ${ }^{3}$.

Relacionados à escola, cada dia mais temos visto notícias como a do dia 12/08/11:

Aluno que mata aula virou caso de polícia no interior de São Paulo: Em Fernandópolis, a vara de infância e da juventude determinou que a polícia deve procurar pelos alunos fujões. Os pais são advertidos e podem levar multas que vão até oito mil reais (Golfieri, 2011).

Nesse caso, a jornalista relata que essa é uma determinação do juiz da cidade de Fernandópolis - SP, Evandro Pelarin, que determinou "à caça" pelos policiais da cidade às crianças e aos adolescentes que não estão na escola, em horário de aula. No período de divulgação da 
reportagem, um adolescente já tinha sido flagrado em uma lan house 4 . Como medida, eles fizeram um boletim de ocorrência, acionaram o Conselho Tutelar e os pais do garoto.

Usaremos, ainda, um exemplo encontrado nos estudos de Passetti (2011). Ele cita a busca gradual das escolas por Conselhos Tutelares (CT) para o encaminhamento de crianças que possuem comportamento desobediente -antes "tratados" por meio de práticas psicopedagógicas. De acordo com Augusto (2009), os Conselhos Tutelares, desde a promulgação do Estatuto da Criança e do Adolescente, atuam através de ações de representantes eleitos pela comunidade que possuem as funções de fiscais e juízes dos atos relacionados às crianças, aos adolescentes e às suas famílias, vigiando, denunciando, advertindo e até sancionando situações como: "indisciplina escolar, desobediência na família, descumprimento de direitos da criança, negligências contra a criança etc." (p. 18).

Ao procurarmos referências sobre a "judicialização na escola", não só este estabelecimento recorre à justiça para a resolução de problemas vividos, por exemplo, no âmbito escolar, como nos relata Marafon (2010), algumas vezes, são os pais que procuram os Conselhos para denunciar eventos ocorridos no colégio. A autora relata que um aluno contou para a mãe que havia sofrido violência sexual na escola por um menino mais velho. Assim, ela procura o CT para resolver a situação. Marafon (2010), ao analisar a situação, diz:

Desqualificando a escola, as conselheiras recusam-se a conhecer qualquer informação que amplie os horizontes da situação já focalizada com as lentes que identificaram como um ato de violência (sexual). Exigiram a retirada do adolescente de sua sala de aula e promoveram o seu encaminhamento à casa da família, informando a direção da escola que o mesmo seria transferido a uma outra unidade

escolar. Para quê?

Nem a escola, nem a família foram informadas do por quê. (...)

(Marafon, 2010, p. 11).

A autora continua o relato afirmando que o Conselho exigiu que o menino fosse para outra escola, baseado em seu direito de estudar, prescrito no Estatuto da Criança e do Adolescente. Isso em meados de outubro. Acha-se outro espaço para os estudos do menino e se exige um direito que já estava sendo concedido pela escola anterior, que era próxima a sua casa.

Nossa sociedade é incapaz "de lidar com forças adversas, de modo que expulsá-las passa a ser o meio de se chegar à purificação do mal" (Passetti, 1999, p. 60). E o poder jurídico faz isso de forma muito 
eficaz!

Nossos exemplos não param por aqui. Podemos citar ainda pessoas recorrendo aos juizados em busca do seu "direito à saúde" requerendo alguns medicamentos que não são cedidos pelo Estado. $O$ direito a saúde foi uma das grandes conquistas do movimento social brasileiro, garantido pela Constituição de 1988 que serviu como base para a implementação do Sistema Único de Saúde (SUS), através da Lei 8.080/90 que definiu a saúde como direito de todos e dever do Estado.

Nessa busca pelo direito à saúde, como nos aponta Junges (2009; 2010), parece que as pessoas estão reconhecendo este direito como direito do consumidor, vendo a saúde apenas em seu aspecto curativo, e não mais como um direito social em que são partes fundamentais a prevenção, a educação e a promoção da saúde, como pensado pelos movimentos sociais nos momentos antecedentes a promulgação da Constituição de 1988. As pessoas pleiteiam ao Estado o acesso ao consumo de tecnologias que oferecem saúde, exigindo, por exemplo, tratamentos que não estão na lista do SUS, mas que poderiam ser substituídos por outras terapêuticas que são concedidas pelo Estado, por causa do lobby das indústrias farmacêuticas por determinadas marcas.

\section{3 "Não acomodar com o que incomoda" 5}

As questões apresentadas são apenas alguns exemplos que nós escolhemos trazer e que estão problematizadas de maneira muito coerente por cada um dos autores que apontamos. Quisemos, com eles, mostrar o quanto temos pedido a intervenção jurídica em nossas vidas, o quanto recorremos a essa instância, para "retomarmos o poder" nas diversas esferas sociais (Reis, 2010).

Diante do exposto, percebemos que as Penas e Medidas Alternativas estão na extremidade do processo. Numa sociedade em que nos tornamos juízes cotidianos ou que buscamos cada vez mais o julgamento dos juízes de Direito para os problemas que encontramos em nosso dia a dia, quando há a efetivação de uma sanção penal para esses pequenos delitos, observamos que eles serão penalizados com as PMAs. Entendemos que elas são um dos efeitos dos processos de judicialização da vida e também um dispositivo do poder de regulamentação da vida. Recorrer ao jurídico é uma das facetas de nossa postura judicializante cotidiana, que produz assujeitamento e perda da potência criadora. "Nesta roda-viva, os cidadãos pouco reparam nas inventivas soluções que eles próprios encontram no dia a dia para resolver as infrações cometidas, e muitas vezes diluem suas atitudes abolicionistas conciliadoras para com a situaçãoproblema (...)" (Passetti, 2006, p. 91). 
São práticas produzidas numa sociedade que predomina a cultura do castigo e da vingança e problematizá-las torna-se um grande desafio tendo em vista a naturalidade com que são entendidas. Precisamos criar outras estratégias para lidar com aquilo que nos incomoda, não perpetuando práticas que recorram aos tribunais formalmente estabelecidos ou àqueles que estão em nós, "fazendo-nos ora juízes, ora acusados, algozes e vítima" (Augusto, 2011). Modificando nossos costumes repressores, nossa vontade punitiva, podemos inventar uma sociedade mais potente, no sentido de abertura a um campo do sensível, a uma alteridade (Passetti, 2006).

Esses são apenas alguns braços desse fenômeno tão complexo que parece abraçar nossas vidas, mas que podemos lutar diariamente para a criação de outras lógicas e, consequentemente, de outra sociedade.

Queremos salientar, ainda, que a judicialização da vida é um processo bastante complexo e que, portanto, dependendo das relações que encontramos pela frente teremos nuances diferenciadas para seus efeitos, por isso afirmamos uma pesquisa que deve ser sempre local e situada. Assim, dependendo do campo que entramos e do foco que damos, a judicialização pode, inclusive, ser vista como um processo completamente diferente do que apresentamos nessas páginas.

Gostaríamos de afirmar, com este trabalho, que "não encontramos precisamente dois opostos a partir dos quais veríamos o bom caminho de um lado e o mau caminho do outro, garantindo-nos a possibilidade de escolher a saída mais condizente com nosso ser" (Orlandi, 2002, p. 234). Não há dualismos. Estamos imersos em um labirinto muito mais complexo do que se apresentam as bipolaridades. Em relação a um código moral (Foucault, 1985), não há a única opção, de cumpri-lo ou não, mas infinitas formas de vivêlo - inclusive, inventando outros modos.

Desse modo, entendemos a ética como um exercício crítico constante (Rodrigues \& Tedesco, 2009). É, a cada momento, diante das determinações dadas pelos códigos sociais, sejam eles materializados em instrumentos jurídicos ou não, pensarmos o que estamos fazendo de nossas vidas ou o que eu estou levando o outro a fazer da vida dele: se atuo num jogo de poder, onde há possibilidade de liberdade, de reversibilidade, de contestação, de criação de outras regras (mais adequadas para aquela forma de vida) ou se minha atuação se dá como forma de dominação.

(...) Estaríamos diante da afirmação do pensamento enquanto uma multiplicidade dispersa. As perguntas não páram de se desdobrar em infinitos pontos e as respostas transformam-se incessantemente em novas perguntas, não constituindo-se nem mesmo como respostas mas como movimento próprio às formas de pensar problematizante. Momento que faz toda 
afirmação ser provisória e move o pensamento a trabalhar sempre no limite da ignorância. Um jogo dos problemas e das perguntas que apresenta ao pensamento o desafio de estabelecer uma outra relação com as regras, retirando-as do plano transcendente e construindo seus sentidos no imanente (Machado, 1999, p. 152).

Pensar que os códigos, as formas de se comportar diante deles, as margens que estabelecemos diante das regras que seguimos, a forma como nos constituímos, que todos esses elementos são produtos de uma história e, portanto, podem ser diferentes, é apostar na invenção de outros códigos, novas margens, outras formas de agir diante das regras sociais, outras maneiras de estar no mundo. Como nos lembra Machado (1999) "a história é invenção porque nada é absoluto .... Cada época enfrenta seus problemas e cria as suas soluções .... Assim, as verdades são provisórias e aparecem tanto como instrumento de dominação quanto de resistência" (p. 158).

Quando pensamos no curso "Exercendo Cidadania" ou nas outras formas de cumprimento das PMAs, quando elas acontecem sem que se problematize, que se reflita o que estamos fazendo de nós mesmos e do mundo, quando elas são apenas o cumprimento do que é estabelecido pelo juiz, estamos diante de uma prática moral (na sua dimensão aprisionadora apresentada por Foucault, 1985), em que não podemos considerar o sujeito como sujeito de ação, "pois esse não refletiu sobre seu ato, apenas agiu, se submetendo à palavra de ordem. Esse sujeito não pode ser considerado livre, mas sujeitado" (Rodrigues \& Tedesco, p. 84, 2009).

Essa análise não diz respeito apenas ao apenado, mas a sociedade em sua ânsia de castigo, de cumprimento de códigos a risca, na imposição de "certa" verdade para todos. Uma sociedade que não questiona seu modo de funcionamento, que enxerga na atitude do outro (que não age como se espera) somente a "falta" e não uma outra forma de existir, uma sociedade que pretende abolir toda forma de diferença, é uma sociedade sujeitada, escrava.

No caso, o que importa não é se a ação foi conforme ou não a regra, como no caso do sujeito jurídico, mas se o questionamento, a experiência modificadora de si teve lugar.... Quando a orientação é ética a subjetivação não passa pela adequação a uma norma ou lei preestabelecidas. Passará por uma problematização de si que permite agir não apenas em função da exigência da lei, mas em função do tipo de relação consigo que pode estabelecer em suas ações (Rodrigues \& Tedesco, p.84, 2009). 
Práticas profissionais que consideram a periculosidade das pessoas, atribuindo a elas uma essência, são práticas que escravizam, traçam um futuro como algo inevitável; práticas sociais que julgam tendo por base um ato que os sujeitos cometeram são práticas cruéis que aprisionam os sujeitos ao tempo, impedindo que a vida continue seguindo em sua natural imprevisibilidade. Precisamos a cada momento nos perguntar "que estamos ajudando a fazer de nós mesmos em nossa imersão nos dispositivos de saber e de poder?" (Orlandi, 2002, p. 222).

Não podemos pensar que qualquer caminho é definitivo. Ele pode até não ter volta (não podemos voltar ao passado, é claro), mas logo em frente, encontramos pontos de bifurcação, outros possíveis, que podem nos levar para lugares onde teremos bons encontros ${ }^{6}$.

E como nos diz Orlandi (2002), a avaliação do que estamos ajudando a fazer de nós mesmos, do que estamos ajudando a fazer do mundo, precisa ser sempre retomada "no nível de cada tentativa". Portanto, pensando nas Penas Alternativas tradicionais ou mesmo no curso que relatamos em nossa pesquisa, que se configura como uma nova tentativa de se operacionalizar as PMAs, precisamos ter sempre uma postura inquietante, problematizadora - características de uma atitude ética, que exige coragem de arriscar-se num novo modo de agir, num novo caminho, numa nova forma de caminhar (Rodrigues \& Tedesco, 2009). Coragem, inclusive, de questionar o sentido do castigar, tão naturalizado no contemporâneo.

Os combates que se dão nesse plano [da imanência] substituem as perguntas caudatárias de um modelo por aquelas, nietzschianas, que vasculham o circunstancial, o acontecimental, o ocasional: quem? O quê? Onde? Por quais meios? Por quê? Como? Quando? O que essas perguntas pedem não é idêntico. Elas acabam por identificar, sim, mas identificam os diferenciais de alianças e dissensões no combate. Elas imanentizam o essencial. É em face delas, a cada instante e a cada tentativa que retorno à pergunta de difícil resposta: que estou ajudando a fazer de mim mesmo? (Orlandi, 2002, p. 236).

São essas as perguntas que inspiraram nossa caminhada e nossa reflexão enquanto caminhávamos. São elas que servirão de foco em cada nova tentativa, tanto quando começamos uma caminhada por outros territórios, quanto para nossos passos diários nos territórios já constituídos.

Lembramos, por fim, que muitas outras trilhas se fazem diariamente pela audácia daqueles que se atrevem a enfrentar caminhos ainda não habitados, com matagais altos; ou, quem sabe, aqueles que, 
aventureiros, encaram densas florestas, mesmo quando todos dizem que por ali não dá para passar.

\section{Referências}

Almeida, F.M. de (2005). Heranças perigosas: arqueologia da periculosidade na legislação penal brasileira. Dissertação de Mestrado em Sociologia, Universidade Federal do Rio Grande do Sul, Porto Alegre, RS, Brasil.

Altoé, S. (2004) Objeto e método da análise institucional. In Altoé, S. René Lourau: analista institucional em tempo integral (pp. 66-86). São Paulo: HUCITEC.

Alves, K.V. (2008) Os discursos da plenitude em educação: uma arqueogenealogia das práticas intelectuais universitárias hoje (Projeto de Pesquisa para Qualificação no curso de doutorado, 2008), Recife, PE, Programa de Pós Graduação em Educação, Universidade Federal de Pernambuco. Recuperado em 23 outubro, 2011, de: $<$ http://elogica.br.inter.net/ferdinan/karinamirian_com2.pdf> Araújo, I. L. (2007). Formação discursiva como conceito chave para a arqueogenealogia de Foucault. Revista Aulas, (3), 130-144.

Augusto, A. (2009). Juridicialização da vida ou sobrevida? Mnemosine, 5(1), 11-22.

Augusto, A. (2011). Juridicialização da vida e sobrevida. Conferência proferida no I Colóquio Internacional Michel Foucault: a judicialização da vida. UERJ. Recuperado em 19 outubro, 2011, de: <http://foucaultjudicializacao.com. br/archives/category/resumos>

Batista, N. (2007) "Só Carolina não viu" - violência doméstica e políticas criminais no Brasil. In A. R. de Mello (Org). Comentários à lei de violência doméstica e familiar contra a mulher ( $p p$. ix-xxiii). Rio de Janeiro: Lumen J uris Editores.

Batista, V. M. (2012). Adesão subjetiva à barbárie. In Loïc Wacquant e a questão penal no capitalismo neoliberal. Rio de Janeiro: Revan.

Batista, V. M. (2009). Criminologia e Política Criminal. Passagens: Revista Internacional de História Política e Cultura Jurídica, 1(2), 20-39. Bocco, F. (2009). A psicologia no Estado Penal: possibilidades e estratégias para subverter a judicialização. In C. M. B. Coimbra, L. S. M. Ayres, M. L. do Nascimento. Pivetes: encontros entre a psicologia e o judiciário. Curitiba: Juruá.

Brasil (2006) Manual de monitoramento das penas e medidas alternativas. Brasília: Secretaria Nacional de Justiça, Central Nacional de Apoio e Acompanhamento às Penas e Medidas Alternativas. Recuperado em 15 março, 2010 de: $<$ http://portal.mj.gov.br/main. asp?View $=\{47 \mathrm{E} 6462 \mathrm{C}-55 \mathrm{C} 9-457 \mathrm{C}-$ 99EC-

5A46AFC02DA7\} \&BrowserType =NN\&LangID =ptbr\&params=itemI D\% 3 
D\% 7B42E17C30-556C-42EF-92C2-

D32DC5D7F5B2\% 7D\% 3B\&UI PartUI D=\% 7B2868BA3C-1C72-4347-

BE11-A26F70F4CB26\% 7D>

Brasil, Congresso Nacional, Câmara dos Deputados (2009) Comissão parlamentar de inquérito do sistema carcerário. CPI sistema carcerário. Brasília: Edições Câmara. Recuperado em 01 novembro, 2011 de <http://bd.camara.leg.br/bd/handle/bdcamara/2701>.

Bruno, D. D. (2009) Judicialização e desjudicialização: duas faces do mesmo fenômeno. In Resumos do II Encontro Estadual Sociojurídico - Atribuições do Serviço Social e o Trabalho Interdisciplinar. Recuperado em 29 dezembro, 2011 de: <http://www.cressrs.org.br/arquivos/documentos/\% 7BDF97BFF41417-4E35-922D-3DD256909E65\% 7D_artigos_enc_sociojur2.pdf>. Caliman, L. V. (2001). Dominando corpos, conduzindo ações: genealogias do biopoder em Foucault. Dissertação de Mestrado em Saúde Coletiva. Universidade Estadual do Rio de Janeiro, Rio de Janeiro, RJ, Brasil.

Conselho Nacional De Justiça (2010). Justiça Criminal. Recuperado em $20 \quad$ outubro, 2010 de: <http://www.cnj.jus.br/index.php?option=com_content\&view=article\&i $\mathrm{d}=10566 \&$ Itemid $=1147>$

Coimbra, C. M. B. (2009). Modalidades de aprisionamento: processos de subjetivação contemporâneos e poder punitivo. In R.T. Oliveira, \& V. de Matos. Estudos de execução criminal: direito e psicologia. Belo Horizonte: Tribunal de Justiça de Minas Gerais.

Deleuze, G. (1992). Post-scriptum sobre as sociedades de controle. In Deleuze, G. Conversações (pp. 240-247). Rio de J aneiro: ed 34.

Deleuze, G. (1998). As estratégias ou o não estratificado: o pensamento do lado de fora (poder). In G. Deleuze, Foucault (pp. 78100). São Paulo: Brasiliense.

Foucault, M. (1979) Vigiar e punir: nascimento da prisão. Petrópolis: Vozes.

Foucault, M. (1985) História da sexualidade I: a vontade de saber. Rio de J aneiro: Graal.

Foucault, M. (1996) A ordem do discurso. São Paulo: Loyola.

Foucault, M. (2000) A arqueologia do saber. Rio de J aneiro: Forense.

Golfieri, D. (2011) Aluno que mata aula virou caso de polícia no interior de São Paulo. Recuperado em 19 de dezembro de 2011 de: <http://g1.globo.com/jornal-hoje/noticia/2010/08/aluno-que-mata-

aula-virou-caso-de-policia-no-interior-de-sao-paulo.html>

J ornal Do Federal (2011). Drogas: cidadania e cuidado são chaves para a psicologia ano XXIII (102), pp. 4-7. Conselho Federal de Psicologia, Brasil.

Junges, J. R. (2009). Direito à saúde, biopoder e bioética. Interface Comunicação, Saúde, Educação, 13(29), 285-295.

Junges, J. R. (2010). Agenciamentos comunitários e biopolíticos do 
direito à saúde. Anais do XI Simpósio Internacional IHU: O (Des)Governo Biopolítico da Vida Humana (1 cd). São Leopoldo, RS, Brasil.

Machado, L. D. (1999). Subjetividades contemporâneas. In E. Barros (Org). Psicologia: questões contemporâneas. Vitória: EDUFES.

Marafon, G (2010). Judicialização da vida escolar e reivindicação de direitos: o que se apresenta e o que pode ser reinventado? Anais do XI Simpósio Internacional IHU: O (Des)Governo Biopolítico da Vida Humana ( 1 cd). São Leopoldo, RS, Brasil.

Moreira, L. R., Figueiredo, T. F. de, Uziel, A. P., Bicalho, P. P. G. de. (2010) A Construção da Psicopatia no Contexto da Cultura do Medo. Revista de Psicologia da IMED 2(1), 297-306, Passo Fundo: Escola de Psicologia da Faculdade Meridional.

Orlandi, L. B. L. (2002). Que estamos ajudando a fazer de nós mesmos? In M. Rago, L. B. L. Orlandi, A. Veiga-Neto (Orgs.). Imagens de Foucault e Deleuze: ressonâncias nietzschianas (pp. 217238). Rio de Janeiro: DP\&A.

Passetti, E. (1999). Sociedade de controle e abolição da punição. São Paulo em Perspectiva, 13(3), 56-66.

Passetti, E. (2006). Ensaio sobre um abolicionismo penal. Verve, (9), 83- 114.

Passetti, E. (2009). Sobre sociedade de controle, educação e fluxos. In: S. Tedesco \& M. L. Nascimento (Orgs). Ética e subjetividade: novos impasses no contemporâneo (pp. 156-168), Porto Alegre: Sulina.

Passetti. E. (2011) Governamentalidade, crianças e violências. In Resumos do I Colóquio Internacional Michel Foucault: A Judicialização da Vida. Recuperado em 19 outubro, 2011 de: <http://foucaultjudicializacao.com.br/archives/category/resumos> Reis, E. F. (2010). A judicialização da vida. Anais do XI Simpósio Internacional IHU: O (Des)Governo Biopolítico da Vida Humana (1 cd). São Leopoldo, RS, Brasil.

Rocha, M. L. da., Aguiar, K. F. de. (2003). Pesquisa-intervenção e a produção de novas análises. Psicologia: Ciência e Profissão, 23(4), 64-73.

Rodrigues, C.\& Tedesco, S. (2009). Por uma perspectiva ética das práticas de cuidado no contemporâneo. In S. Tedesco, M. L. Nascimento (Orgs). Ética e subjetividade: novos impasses no contemporâneo. Porto Alegre: Sulina.

Silva, C. A. (2001). Promotores de justiça e novas formas de atuação em defesa de interesses sociais e coletivos. Revista Brasileira de Ciências Sociais, 16(45), 128-144.

Vaz, P., Sá-Carvalho, C., Pombo, M. (2005). Risco e sofrimento evitável: a imagem da polícia no noticiário de crime. Revista da Associação Nacional dos Programas de Pós-Graduação em Comunicação, (4), 1-22.

Vianna, L. W. (1999). A democracia e os três poderes no Brasil. Belo 
Fabiana Davel Canal, Gilead Marchezi Tavares

Judicialização da vida e penas e medidas alternativas: composições,

tensionamentos, problematizações

Horizonte: UFMG.

Zimmer, F. (2011). Internação compulsória uma nova porta de entrada legal para o asilo. Dissertação de Mestrado em Psicologia Institucional, Universidade Federal do Espírito Santo, Vitória, ES, Brasil.

\section{Endereço para correspondência \\ Fabiana Davel Canal}

CREAS - Rua Manoel Pires Martins, 269. Bairro Santo Andrezinho, CEP 29360-000, Castelo, Espírito Santo - ES, Brasil

Endereço eletrônico: fabidavel@yahoo.com.br

Gilead Marchezi Tavares

PPGPSI (Programa de Pós Graduação em Psicologia Institucional) - UFES

Av. Fernando Ferrari, 514, Goiabeiras, CEP 29075-910, Vitória - ES, Brasil

Endereço eletrônico: gilead.dindin@ig.com.br

Recebido em: 21/03/2012

Reformulado em: 01/07/2013

Aceito para publicação em: 16/07/2013

Acompanhamento do processo editorial: Alexandra Cleopatre Tsallis

\section{Notas}

* Psicóloga. Mestre em Psicologia Institucional pelo Programa de Pós-graduação em Psicologia Institucional da Universidade Federal do Espírito Santo. Professora do Instituto de Ensino Superior do Espírito Santo. Castelo-ES, Brasil.

** Psicóloga. Doutora em Psicologia pela Universidade Federal do Espírito Santo. Professora Adjunta do Departamento de Psicologia e do Programa de PósGraduação em Psicologia Institucional da Universidade Federal do Espírito Santo. Vitória-ES, Brasil.

1 Para Foucault (1985), o termo biopolítica é um dos polos (o outro são os mecanismos disciplinares) de constituição do biopoder. Biopolítica seria um foco de exercício do poder, constituído em meados do século XVIII e assumido por meio de intervenções e controles reguladores das populações. É um campo mais amplo que "centrou-se no corpo-espécie, no corpo transpassado pela mecânica do ser vivo e como suporte dos processos biológicos" (p.131), o que ele denominou de biopolítica das populações. Com a biopolítica e a concepção da regularidade dos fenômenos populacionais, as medidas tomadas pelo Estado não tem mais o caráter definitivo das leis, mas se adaptam aos resultados previsíveis por meio dos mecanismos de segurança, que apontam estimativas, probabilidades. Assim, o investimento sobre a vida, pelo biopoder, é ao mesmo tempo individualizante (atuando no corpo, por meio das disciplinas, a anátomo política do corpo) e totalizante (com o controle da dinâmica das populações ocupando-se das estatísticas, das taxas de natalidade e mortalidade, níveis de saúde etc.). Dessa forma, segundo o autor, faz-se um controle sobre todos e sobre cada um. Há uma intervenção na maneira de se estar vivo, que diz respeito a como viver (Foucault, 1999).

${ }^{2}$ Usamos o termo instituição de acordo com a Análise Institucional francesa. Ela faz uma distinção de instituição para organização ou estabelecimento. Instituição trata-se de um conceito-artifício que engloba toda e qualquer relação que se caracteriza por naturalizar práticas, percebendo-as como naturais, eternas e necessárias que podem se instrumentalizar em estabelecimentos e organizações. Toda instituição tem sempre um lado que a conserva - o instituído - e outro que a contesta e tem a capacidade de criar novas formas - o instituinte (Altoé, 2004).

${ }^{3}$ Nesse sentido, há por parte do Conselho Federal de Psicologia uma campanha pela não internação compulsória, entendendo que essa forma de tratamento do 
Fabiana Davel Canal, Gilead Marchezi Tavares Judicialização da vida e penas e medidas alternativas: composições, tensionamentos, problematizações

dependente químico reatualiza os manicômios. Há a luta por terapêuticas que privilegiem a liberdade e a ampliação por parte do Estado do número de CAPS AD (Centro de Atenção Psicossocial especializado em álcool e outras drogas) e consultórios de rua (Jornal Do Federal, 2011).

${ }^{4}$ Lan house é um local de entreterimento onde existe uma série de computadores ligados em rede.

5 Trecho da música "Criado Mudo", do grupo "Teatro Mágico".

6 "Bom seria a expressão da composição das forças e mau seria a expressão da decomposição das forças. Os corpos e as idéias produzem encontros que poder ter como efeito o aumento ou a diminuição de sua potência. Para Espinosa, o bom, livre ou forte ou sensato, será aquele que se esforça por produzir encontros, por compor forças nas suas relações, por aumentar a potência. Produzir um mais de força - não no sentido de acúmulo de força, mas no sentido de uma maior intensidade das forças ativas - que venha produzir uma outra qualidade de força, uma potência de agir (...)" (Machado, 1999, p. 154). 